\title{
INTERACTION OF OXYGEN WITH AN AISI 314 STAINLESS STEEL SURFACE STUDIED BY ELLIPSOMETRY AND AUGER ELECTRON SPECTROSCOPY IN COMBINATION WITH ION BOMBARDMENT*
}

\author{
G. J. Stokkers, $\S$ A. van Silfhout, $\nmid$ G. A. Bootsma, $\nmid$ T. Fransen ${ }_{\dagger}^{+}$ \\ and P. J. Gellings +
}

\author{
†Department of Applied Physics and ‡Department of Chemical Technology, \\ Twente University of Technology, P.O. Box 217, 7500 AE Enschede, the Netherlands
}

\begin{abstract}
The influence of pretreatment (ion bombardment) on the initial oxidation of AISI 314 stainless steel has been investigated in ultra high vacuum systems with ellipsometry and Auger electron spectroscopy. The bombardment was carried out with $\mathrm{Ar}^{+}$ions with energies up to $2.2 \mathrm{keV}$ at various doses and angles of incidence. Oxidation was performed at low $p_{0 z}\left(<10^{-5}\right.$ Torr $)$ and sample temperatures $\left(<300^{\circ} \mathrm{C}\right)$. The worked layer was removed with low-energy argon ions. High energy bombardment causes an increase in oxidation rate and higher values of the real and imaginary part of the refractive index as compared to the undisturbed sample. The rate and extent of oxidation increases with increasing energy, dose and angle of incidence of the ion beam. The outermost part of the oxide is enriched in iron while the region near the substrate contains more nickel and chromium.
\end{abstract}

\section{INTRODUCTION}

THE OXIDATION of stainless steel has been investigated with various surface analytical techniques such as Auger Electron Spectroscopy (AES), ${ }^{1-3}$ Electron Spectroscopy for Chemical Analysis (ESCA) ${ }^{4}$ and Secondary Ion Mass Spectrometry (SIMS). ${ }^{5}$ Most previous work $\mathrm{K}^{\mathbf{1 , 2}, \mathbf{4}}$ has indicated the important role played by $\mathrm{Cr}$ at higher temperatures $\left(>700^{\circ} \mathrm{C}\right)$. The oxide layer formed at lower temperatures $\left(<600^{\circ} \mathrm{C}\right)$ contains more $\mathrm{Fe}$, while $\mathrm{Cr}$ and $\mathrm{Ni}$ appear only in the region near the substrate. $2,4,5$

Furthermore the oxidation of metals and alloys often is affected by their microstructure ${ }^{6,7}$ Cold work, for instance, is reported to increase the rate of oxidation of pure $\mathrm{Fe}^{6}$ but to reduce that of a Fe-10Cr alloy. ${ }^{7}$ Hossain ${ }^{8}$ showed the effect of mechanical treatments on the high temperature oxidation of a $\mathrm{Fe}-10 \mathrm{Cr}$ alloy. Recent work in our laboratory indicated the influence of the pretreatment (e.g. machining) on the high temperature oxidation behaviour of AISI 314 stainless steel. It revealed the influence of a worked layer and the importance of the initial oxidation stage. Therefore a separate study of this stage with a combination of surface analytical techniques was undertaken. The conditions of oxidation are very special and quite different from the more technical ones in investigations by other authors. ${ }^{2,4,8}$ We used samples cleaned and pretreated in vacuum by $\mathrm{Ar}^{+}$ion bombardment. Oxidation as performed at moderate temperatures (up to $\left.300^{\circ} \mathrm{C}\right)$, low $p \mathrm{O}_{2}\left(\sim 10^{-5} \mathrm{Torr}\right.$ ) and small doses of pure oxygen (up to $5 \times 10^{5} \mathrm{~L}, 1 \mathrm{~L}=10^{-6}$ Torr. $\mathrm{s}=1.33 \times 10^{-4} \mathrm{~Pa} \mathrm{~s}$ ).

Ellipsometric measurements were used to determine in situ the optical parameters of the pretreated stainless steel surface and to monitor the thickness of the oxide as a

*Manuscript received 11 November 1981; in amended form 15 June 1982.

§resent address: AKZO, Hengelo(0), the Netherlands. 
function of time. The chemical composition of the sample surface and of the oxide as a function of thickness was determined by using AES in combination with ellipsometry and ion sputtering. For a detailed description of the techniques we refer to the reviews on ellipsometry ${ }^{10,11}$ and on AES. ${ }^{12,13}$

\section{EXPERIMENTAL METHOD}

The samples were cut from an as-received commercially available stainless steel rod (dia $20 \mathrm{~mm}$, Phönix R1, Vereinigte Edelstahlwerke). According to the manufacturer the composition of this material was (in wt \%): $\mathrm{Cr}, 24.22 ; \mathrm{Ni} .19 .30 ; \mathrm{Si}, 2.10 ; \mathrm{Mn}, 1.29 ; \mathrm{C}, 0.06 ; \mathrm{P}, 0.027 ; \mathrm{S}, 0.005 ;$ balance Fe. The average grain size was $20 \mu \mathrm{m}$. The samples were first ground to the desired thickness, using a series of carborundum papers up to 800 grit. After polishing with diamond paste $(8 \mu \mathrm{m})$ and $\mathrm{Al}_{2} \mathrm{O}_{3}$ paste $(0.05 \mu \mathrm{m})$ they were cleaned ultrasonically in water and ethanol and, prior to mounting in the vacuum system, in propanol-2.

The experiments were performed in two UHV systems. System I consists of a Riber PEG 1000 pumping unit with an integrated $1001 . \mathrm{s}^{-1}$ ion getter pump and titanium sublimator with a watercooled shield and a specially designed vacuum chamber provided with facilities for ellipsometry, ion bombardment and oxygen exposure.

The disc-shaped sample (10 mm dia, $1 \mathrm{~mm}$ thickness) was clamped to a sample holder, which could be heated indirectly by means of a halogen lamp $(12 \mathrm{~V}, 100 \mathrm{~W})$ up to $500^{\circ} \mathrm{C}$. The temperature was measured with a chromel-alumel thermocouple. Sample, thermocouple and clamp were electrically isolated from the sample holder to allow measurement of the ion dose during ion bombardment. A radiation shield, partly surrounding the sample holder, prevented heat losses. The sample holder, mounted on a rod which is attached to a vacuum bellows, allows a small translation in the vertical direction $(\sim 2 \mathrm{~cm})$ and a limited tilt $\left(\sim 5^{\circ}\right)$. For cleaning and pretreatment of the sample two ion guns were used, both operating under normal incidence. On gun (prototype, Philips' Research Laboratories) produced argon ions in the energy range $200-500 \mathrm{eV}$ with a current density of $0.2 \mu \mathrm{A}$ $\mathrm{cm}^{-2}$ at a pressure of $6 \times 10^{-5}$ Torr. The other ion gun (Vacuum Generators, VG-AG2) was capable of producing a higher ion energy and current density $\left(1800-2200 \mathrm{eV}, 0.8 \mu \mathrm{A} \mathrm{cm}^{-8}\right.$ at $4 \times 10^{-8} \mathrm{Torr}$ operating pressure).

Combined AES and ellipsometry experiments were performed in UHV-system II. This system is equipped with facilities for ellipsometry, AES, ion bombardment and oxygen exposure. $A$ more detailed description of this experimental set-up is given in ref. 14. The rectangularly-shaped sample $(25 \times 8 \times 1 \mathrm{~mm})$ was mounted on a modified VG-UMD 1 manipulator. The sample could be treated to $\sim 300^{\circ} \mathrm{C}$ by passing a current through a metal capillary of the holder while flushing it with an inert gas.

A VG-HCMA (Hemispherical Cylindric Mirror Analyzer) was used for AES. The sample cleaning and pretreatment was initially performed by means of a cold-cathode ion gun (VG-AG2). The angle of incidence of the ion beam with respect to the surface normal was 0 or $75^{\circ}$. The residual gas composition was determined with a quadrupole mass analyzer (Riber QMM16).

For both systems a turbomolecular pumping unit (Pfeiffer TSU 100) was available for pumping during ion bombardment and oxygen exposure. Oxygen (99.995\% pure) and argon (99.999\% pure) could separately be introduced in the main vacuum chamber and in the ionization chamber of the jon gun. The base pressures of the systems after bake-out were in the $10^{-10}$ Torr region, measured with a Bayard-Alpert gauge.

The ellipsometric measurements were performed by means of a home-made automatic ellipsometer of the self-nulling type which has been described elsewhere. ${ }^{14}$

In UHV-system I the sample was bombarded with argon ions until no further change in $\Delta$ or $\psi$ was observed. In the other system also AES measurements were used to define the starting surface.

The ellipsometric parameters of the starting surface were determined by means of a four-zone measurement. After introducing oxygen at the desired pressure, the course of the oxidation was followed ellipsometrically in one zone. At the end of an oxidation run another four-zone measurement was performed to calibrate the measured $\Delta$ and $\psi$ changes. In UHV-system II an Auger spectrum was taken after the oxidation. Absolute values of $\Delta$ and $\psi$ were obtained afterwards by determining the correction for the optical window birefringence. A series of four-zone measurements performed in vacuum and at 1 atm $N_{2}$ with and without optical windows gave the desired correction.

The oxidation process was followed by monitoring the changes in the ellipsometric paramoiers $\Delta$ and $\psi$ defined as $\delta \Delta=\bar{\Delta}-\Delta$ and $\delta \psi=\bar{\psi}-\psi \cdot \bar{\Sigma}$ and $\bar{\psi}$ refer to the clean substrate and $\Delta$ and $\psi$ to the substrate covered with a layer. 


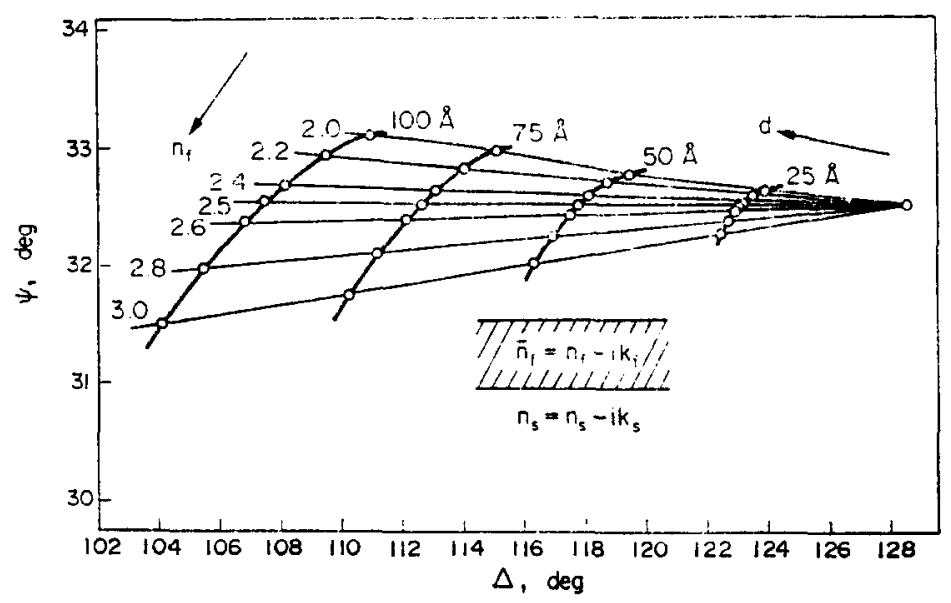

FIG. 1. $\Delta-\psi$ plot calculated for stainless steel substrate with oxide layers. $\lambda=6328 \AA, \varphi_{0}=69.4^{\circ}, \hat{n}_{\mathrm{s}}=2.50-4.03 i, k_{\mathrm{t}}=0.25$.

Assuming that the layer may be approximated as uniform with thickness $d$ and refractive index $\tilde{n}_{t}=n_{t}-i k_{t}$ on a substrate with a refractive index $\tilde{n}_{\mathrm{a}}=n_{\mathrm{a}}-i k_{\mathrm{a}}$ (to be computed from $\bar{\Delta}, \bar{\psi}$ ) it is possible, knowing the wavelength, $\lambda$, and the angle of incidence, $\varphi_{0}$, of the light, to compute a so-called $\Delta-\psi$ plot. ${ }^{\text {ib }}$ Such a plot for our stainless steel substrate with layers with different refractive indices is given in Fig. 1. It turns out that in our experimental $\Delta-\psi$ ranges, $\delta \Delta$ is linearly related to the thickness $d$ of the layer: $\delta \Delta=\zeta d$. The measured changes in $\psi$ are always small $\left(<0.2^{\circ}\right)$ although $\Delta$ changed several degrees. The experimental oxide growth curves are therefore presented as $\delta \Delta$ vs time curves. Using our measured values for $\hat{n}_{8}(2.50-4.03 i)$ and $\tilde{n}_{1}(2.5-0.25 i)$, the proportionality factor is calculated to be $\zeta=0.20-0.22 \mathrm{deg} / \AA$ (cf. Fig. 1).

It may be remarked that this approximation is not valid for the very first stage of oxidation, i.e. the chemisorption of the first monolayer(s) (cf. initial stages of oxidation of semiconductors ${ }^{10}$ and metals $\left.{ }^{17}\right)$.

\section{Influence of the ion dose}

Low-energy argon ion bombardment of the samples in UHV-system I caused an increase in $\Delta$ while $\psi$ remained almost constant and resulted in an apparent optical constant $\tilde{n}_{s}=2.8-4.2 i$.

Thereafter successive oxidation and sputtering cycles were performed in order to determine the influence of the pretreatment on the oxidation behaviour and to remove the worked layer.

The results of the oxidation runs are shown in Fig. 2. The curves are labelled by their cumulative ion bombardment dose. After the first oxidation (curve A) the sample was bombarded until the apparent optical constant $\tilde{n}_{\mathrm{s}}$ was again 2.8-4.2i. The oxidation performed with this surface is represented by curve $B$.

Successive oxidation runs showed a drastic change after an ion dose of $\sim 250 \mathrm{mC} \mathrm{cm}^{-2}$. The fast initial oxidation of the first runs transformed into a much slower oxidation. After ion doses below $250 \mathrm{mC} \mathrm{cm}^{-2}$ the thickness of the oxide layers formed at a given time appeared to be equal. After higher ion doses these thicknesses were about four times smaller.

After a cumulative dose of $\sim 400 \mathrm{mC} \mathrm{cm}^{-2}$ the apparent refractive index $\tilde{n}_{\mathrm{s}}=$ 


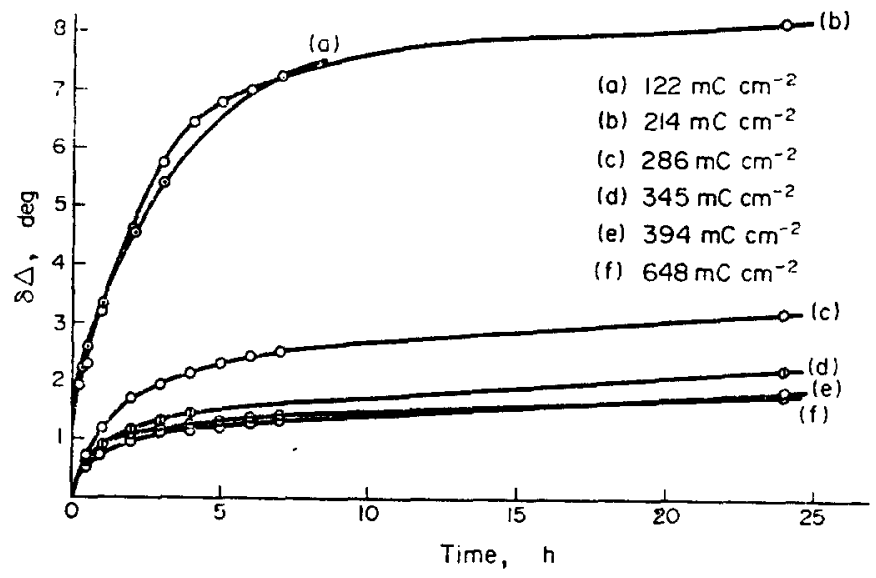

Fig. 2. $\delta \Delta$ as a function of time of exposure to oxygen at a pressure of $7 \times 10^{-8}$ at $25^{\circ} \mathrm{C}$ for cumulative ion doses. $\lambda=6328 \AA, \varphi_{0}=69.4^{\circ}$. Argon ion bombardment conditions: energy $440 \mathrm{eV}$ (curve E: $330 \mathrm{eV}$ ), current density $0.2 \mu \mathrm{A} \mathrm{cm}-2$, angle of incidence $0^{\circ}$.

2.50-4.03i and the oxidation behaviour stabilized again. Variation of the ion energy had no significant influence (curves $E$ and $F$ ).

\section{Influence of ion energy and angle of incidence}

To investigate the influence of the ion energy in system I a second sample was bombarded with $\mathrm{Ar}^{+}$ions of higher energy and current density by using the AG-2 gun until no further changes in $\bar{\Delta}$ and $\bar{\psi}$ were observed $\left(\tilde{n}_{\mathrm{s}}=2.81-4.16 i\right)$. Figure 3 shows an oxidation curve determined at $\sim 200^{\circ} \mathrm{C}$; for comparison the curve obtained in the same conditions after bombardment with ions with a lower energy is also plotted. The figure reveals a large influence of the bombarding conditions on the initial oxidation behaviour, especially in the first stage. Bombarding at high energy resulted in a very fast, almost linear, decrease in $\Delta$ during the first minutes of oxidation. An

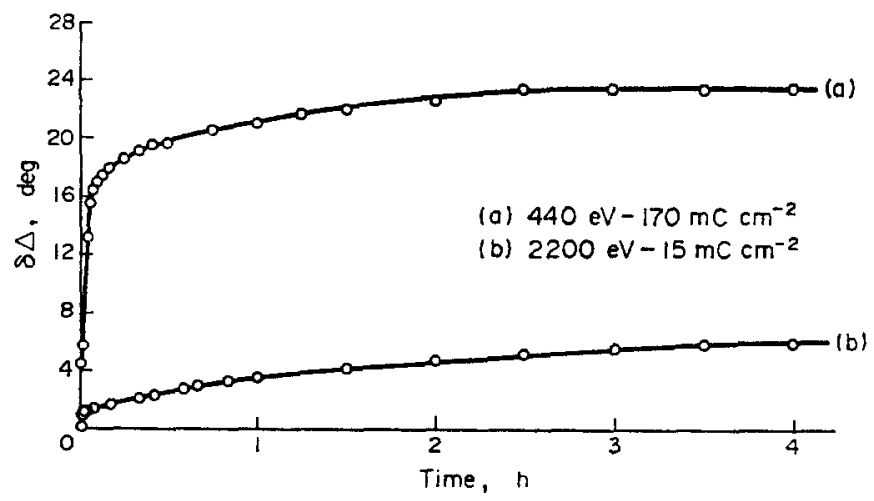

Fig. 3. $\delta \Delta$ as a function of time of exposure to oxygen at a pressure of $7 \times 10^{-6}$ Torr at $\sim 200^{\circ} \mathrm{C}$ for different argon ion bombardment conditions, angle of incidence $0^{\circ}$. 


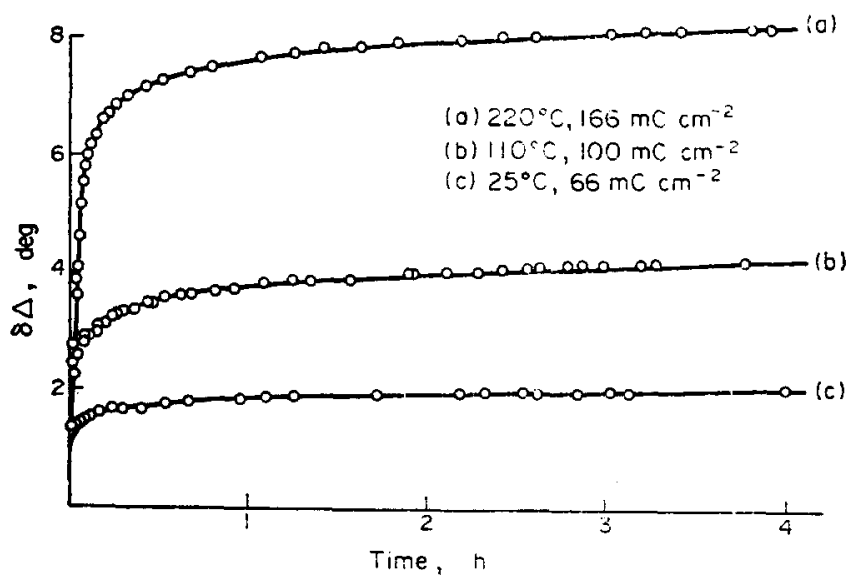

Fig. 4. $\delta \Delta$ as a function of time of exposure to oxygen at a pressure of $7 \times 10^{-8} \mathrm{Torr}$ at different temperatures. Argon ion bombardment conditions: energy $2200 \mathrm{eV}$, current density $0.8 \mu \mathrm{A} \mathrm{cm} \mathrm{cm}^{-2}$, angle of incidence $75^{\circ}$.

oxide layer with a thickness of $\sim 80 \AA$ was formed during the first $5 \mathrm{~min}$ in contrast with the thickness of $\sim 7 \AA$ after bombardment with ions with lower energy.

In UHV system II two samples were bombarded with $\mathrm{Ar}^{+}$ions of about $2 \mathrm{keV}$ at two angles of incidence $\left(0\right.$ and $\left.75^{\circ}\right)$. Oxidation runs were carried out at an oxygen pressure of $7.10^{-6}$ Torr at different sample temperatures. The results of these experiments are given in Figs 4 and 5. At all temperatures in Fig. 4 a fast initial increase in oxide thickness during the first $20-40 \mathrm{~min}$ of exposure was followed by a much slower increase.

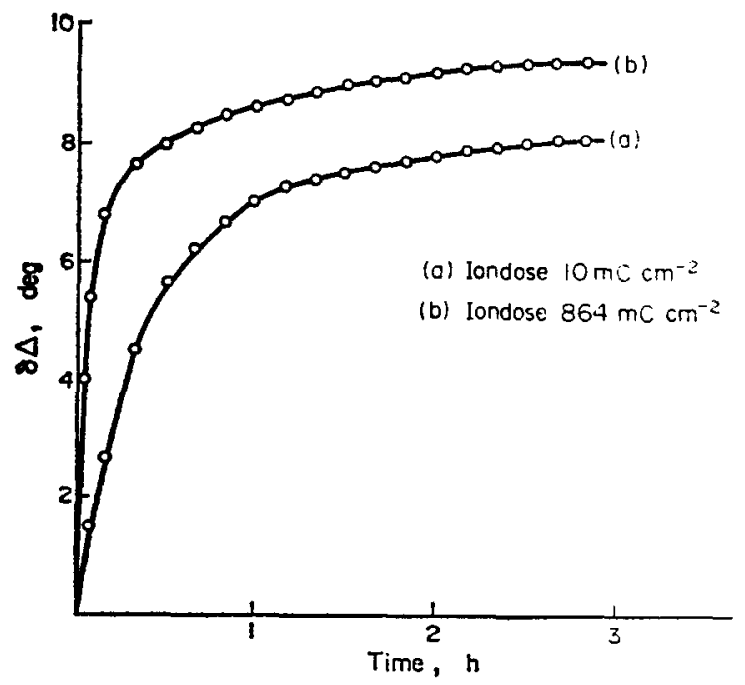

Fig. 5. $\delta \Delta$ as a function of time of exposure to oxygen at a pressure of $7 \times 10^{-6} \mathrm{Torr}$ at $200^{\circ} \mathrm{C}$. Argon ion bombardment conditions: energy $2000 \mathrm{eV}$, current density $0.5 \mu \mathrm{A} \mathrm{cm}^{-2}$, angle of incidence $0^{\circ}$. 
The first, almost linear, part of the curve appeared to be independent of the temperature of oxidation. After bombardment at normal incidence the initial oxidation rate appeared to depend on the ion dose (Fig. 5). Comparison of curves A in Figs 4 and 5 shows that the initial oxidation rate is larger after bombardment at glancing incidence of the ion beam.

\section{Composition of the oxide layer}

The composition of the surface layer after bombardment and oxidation runs was monitored with AES. Two representative spectra, obtained before and after oxidation run $C$ in Fig. 4, are given in Fig. 6. The spectrum of the bombarded surface shows the major constituents of the stainless steel ( $\mathrm{Fe}, \mathrm{Cr}$ and $\mathrm{Ni}$ ). Moreover, a large carbon peak at $272 \mathrm{eV}$ is present, which may have been due to segregation of carbon from the bulk of the sample. The relative height of this peak decreased with increasing temperature. Furthermore a small nitrogen peak at $\sim 385 \mathrm{eV}$ was detected. Whether this peak was caused by sorption of $\mathrm{N}_{2}$ or by the presence of $\mathrm{Cr} / \mathrm{Fe}$ nitride in the stainless steel is unknown. The observation that the peak was more pronounced at higher temperatures makes the latter more plausible. The oxygen peak at $510 \mathrm{eV}$ was always observed, although its height became smaller after prolonged bombardment. The small peak located at $215 \mathrm{eV}$ may be attributed to argon, implanted during the ion bombardment. The Auger spectra registered after oxidation of the sample showed a large oxygen peak located at $510 \mathrm{eV}$ and, in strong resemblance with the standard spectra for e.g. $\mathrm{MgO},{ }^{18}$ a smaller one at $490 \mathrm{eV}$.

Comparison of the spectra for bombarded and oxidized surfaces revealed the following features: (i) the carbon peak, which is clearly visible for the bombarded surface became much smaller for the oxidized surface, (ii) at the oxide surfaces nickel

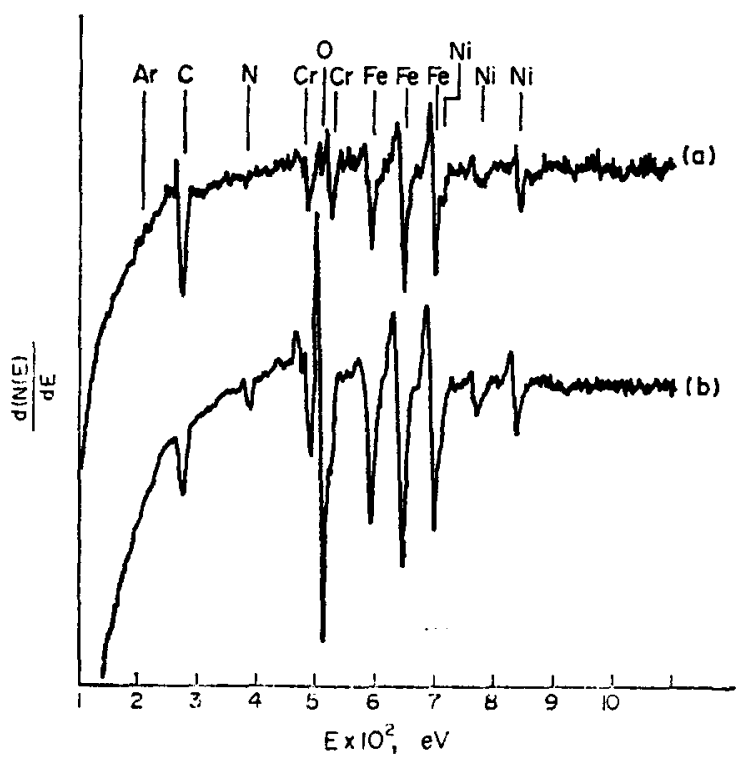

FIG. 6. Auger spectra obtained before (A) and after (B) oxidation run $\mathrm{C}$ in Fig. 4. 


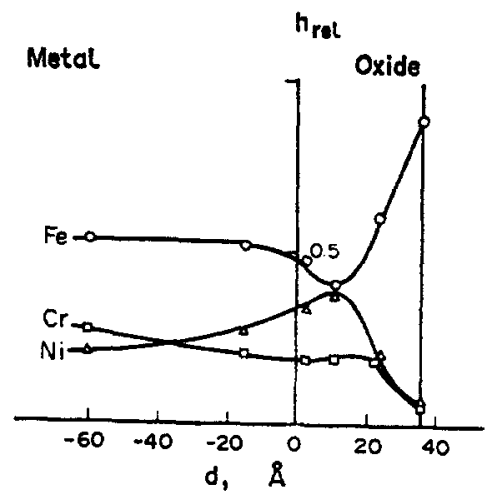

FIG. 7. Relative Auger peak height $\left(h_{\mathrm{Iet}}\right)$ as a function of the position with respect to oxide-steel interface.

was present only in minor quantities, whereas it was clearly detectable at the bombarded surfaces, and (iii) the situation with respect to chromium is less clear due to the overlap of the oxygen peaks at 490 and $510 \mathrm{eV}$ and the chromium peaks located at 489 and $529 \mathrm{eV}$. The spectra for the surfaces oxidized at the lower temperatures clearly showed the $529 \mathrm{eV}$ chromium peak as a shoulder at the high energy side of the $510 \mathrm{eV}$ oxygen peak. This shoulder was absent in the AES spectrum of the surface oxidized at $220^{\circ} \mathrm{C}$; moreover, the ratio of the peak heights at 490 and $510 \mathrm{eV}(0.21)$ was almost identical to that of the oxygen peaks in the standard spectrum of $\mathrm{MgO}^{18}(0.19)$. This indicates the absence of chromium at $220^{\circ} \mathrm{C}$. For the lower temperatures a corrected chromium peak was computed by subtracting $20 \%$ of the height of the $510 \mathrm{eV}$ peak from the measure height of the peak at $490 \mathrm{eV}$. The oxide surface showed a lower chromium content also at $25^{\circ} \mathrm{C}$. The depth profile of the oxide layer formed at $220^{\circ} \mathrm{C}$ (curve A, Fig. 4) was determined at room temperature by applying alternate bombardment and AES cycles. During bombardment the thickness was monitored by means of ellipsometry by using the relation $d(\AA)=4.75 \delta \Delta(\mathrm{deg})$.

The Auger spectra were interpreted by comparing the relative heights of the peaks of chromium (corrected peak at $490 \mathrm{eV}$ ), iron $(650 \mathrm{eV})$ and nickel $(850 \mathrm{eV})$, defined as the ratio of their heights to the sum of the heights of the three peaks. Figure 7 shows the relative peak heights $\left(h_{\mathrm{ret}}\right)$ as a function of the position relative to the oxide-steel interface. The positions in the oxide layer were determined from the ellipsometric measurements, those in the steel were calculated from the ion dose assuming yield of $\sim 1$ atom/Ar+ ion. ${ }^{10}$ From Figure 7 it follows that the outermost part of the oxide layer consists mainly of iron oxide. The nickel peak shows a maximum at $\sim 10 \AA$ from the oxide-steel interface while this region shows a lower iron content.

\section{DISCUSSION}

\section{Pretreatment and oxidation behaviour}

Apart from sputtering, ion bombardment with medium encrgetic ions can induce other changes in solids, namely ion implantation, surface roughening and structural disordering of a layer at the surface. These changes are known to affect the oxidation behaviour, e.g. for bombardment of polycrystalline iron with $8 \mathrm{keV}$ argon ions a 
passivating as well as an accelerating influence has been reported, depending on preoxidation of the surface and ion dose. ${ }^{20}$

The increase in oxidation rate is usually supposed to originate from the defects introduced and the roughening of the surface. According to the literature ${ }^{6,8}$ the presence of a worked layer after grinding and polishing of a pure metal generally also causes an increase in oxidation rate as a result of the introduction of vacancies, interstitials and dislocations.

The decrease in oxidation rate at a cumulative dose of $>250 \mathrm{mC} \mathrm{cm}^{-2}$ described in the results section (Fig. 2) may be associated with the removal of the worked layer. The penetration depth of the low-energy $(\sim 500 \mathrm{eV})$ argon ions used in this process is known to be of the order of a few atomic layers ${ }^{19}$ and therefore implantation will hardly take place, cf. ref. ${ }^{5}$. Taking a sputter yield of 0.15 atom $/ \mathrm{Ar}^{+}$ion for the oxide (our measurement), a yield of 1 atom/ion for the metal ${ }^{18}$ and a typical atomic volume of $\sim 10 \AA^{3}$, the thickness of the working layer may be estimated by taking into account the succession of sputtering and oxidation cycles (Fig. 2). For a total ion dose of $250 \mathrm{mC} \mathrm{cm}^{-2}$ this calculation yields a thickness of $\sim 1000 \AA$. This estimate is in good agreement with the value derived from the diameter of the $\mathrm{Al}_{2} \mathrm{O}_{3}$ particles used in the final polishing stage $(0.05 \mu \mathrm{m})$ if, as has been observed earlier, ${ }^{21}$ the thickness of the damaged layer is thought to be equal to about two times the grain size.

Table 1 gives a survey of the real and imaginary parts of the complex refractive index as computed from $\bar{\Delta}$ and $\bar{\psi}$ after correction for window birefringence. The similarity of the worked layer and ion bombarded layers is reflected in the values of the refractive index and in the oxidation behaviour. Since the penetration depth of the light at $6328 \AA$ for $k=4.0-4.4$ amounts to $\lambda /(4 \pi k) \sim 120 \AA$, the refractive index measured in the presence of the worked layer (2.8-4.2i) may be ascribed to this very layer. We assume that the values of $n$ and $k$ obtained after removal of this layer with the $440 \mathrm{eV}$ ions (215-4.0i) are most close to those of undisturbed, clean stainless steel. The frequently applied annealing of materials after ion bombardment has been avoided because heating above $400^{\circ} \mathrm{C}$ introduces drastic changes in the surface composition, i.e. a higher chromium content causing a decrease in the oxidation rate. ${ }^{5}$

Table 1 shows that both polishing and bombardment with $2 \mathrm{keV}$ ions resulted in an increase of $n$ and $k$ with respect to the "undisturbed" sample. For polishing and compacting of chromium this effect has earlier been observed by Hill and Weaver. ${ }^{22}$

TABLE 1. REFRACTIVE INDEX OF AISI 314 STEEL MEASURED AFTER DIFFERENT PRETREATMENTS

\begin{tabular}{cccccc}
\hline UHV system & $\begin{array}{c}\text { Angle of } \\
\text { incidence } \\
\text { ion beam }\end{array}$ & $\begin{array}{c}\text { Ion dose } \\
\left(\mathrm{mC} \mathrm{cm}^{-2}\right)\end{array}$ & $\begin{array}{c}\text { Ion energy } \\
(\mathrm{keV})\end{array}$ & $\boldsymbol{n}_{\mathbf{s}}$ & $k_{\text {s }}$ \\
\hline \multirow{2}{*}{ I } & $0^{\circ}$ & $<250$ & $<0.5$ & 2.80 & 4.23 \\
& $0^{\circ}$ & $>350$ & $<0.5$ & 2.50 & 4.03 \\
II & $0^{\circ}$ & $<250$ & 2.2 & 2.81 & 4.16 \\
& $0^{\circ}$ & $<100$ & 2.0 & 2.87 & 4.25 \\
& $0^{\circ}$ & $>500$ & 2.0 & 2.99 & 4.37 \\
\hline
\end{tabular}


An interpretation of the shifts in the optical constants upon damaging may be given in terms of the effective medium theory, as applied by Aspnes et al. to $\mathrm{Au}^{23}$ and $\mathrm{Ge}^{24}$. An increase in both $n$ and $k$ upon bombardment has also been reported by other authors, e.g. for $\mathrm{Si}^{14}$ and $\mathrm{GaAs} .{ }^{25} \mathrm{~A}$ satisfactory interpretation requires the use of spectroscopic ellipsometry.

The extent of the damaged layer and the density and nature of the damage depend on the conditions of the bombardment, i.e. energy, ion dose, current density and angle of incidence of the ions. The preliminary data in Table 1 show larger deviations from the undisturbed case at higher ion energy, higher ion dose and at glancing incidence.

Both the presence of the worked layer and preceding bombardment with $2 \mathrm{keV}$ ions with different dose and angle of incidence resulted in a larger and faster change in $\Delta$ during the first stage of oxidation as compared with the surface pretreated with $440 \mathrm{eV}$ ions (Figs 2-5). The results obtained for the worked layer and after bombardment with a small ion dose at normal incidence are comparable, in line with the optical constants (Table 1). Comparison of the optical constants and oxidation behaviour of the surfaces pretreated in UHV system II with an $\mathrm{Ar}^{+}$ion dose of $<100 \mathrm{mC} \mathrm{cm}$ at $2 \mathrm{keV}$ and an ion dose of $>500 \mathrm{mC} \mathrm{cm}^{2}$ at the same energy suggests the occurrence of some type of oxidation accceleration in the last case (see Fig. 5). A same effect appears between normal and glancing incidence bombardment of $\mathrm{Ar}^{+}$ ions at higher energy (Figs 4 and 5, Table 1). The difference in refractive index and oxidation behaviour of the samples in UHV systems I and II after bombardment with a small ion dose $\left(<300 \mathrm{mC} \mathrm{cm}^{-2}\right)$ at higher energy $(\sim 2 \mathrm{keV})$ may be due to the orientation difference of the samples and the differences in current density of the ion beams.

\section{Oxide layer}

The AES results show that in the temperature region used here the outerpart of the oxide film is mainly composed of iron oxide, in agreement with refs. ${ }^{2,4,5}$. A recent AES-study of a $17 / 13$ stainless steel ${ }^{3}$ has shown that several stages may be distinguished in the adsorption of oxygen on a clean stainless-steel surface $\left(25^{\circ} \mathrm{C}, \mathrm{pO}_{2} 10^{-8} \mathrm{Torr}\right)$. At low exposures the chemisorption of oxygen occurs preferably on the chromium sites, while iron remains in the metallic state. Thereafter a reconstruction of the surface takes place and iron atoms, moved to the top layer by a place-exchange mechanism, now interact with oxygen. The increase in oxidation rate observed in the presence of the working layer and after the high energy bombardment can be explained by assuming that the reconstruction process is facilitated by the damage introduced. The refractive index of the oxide giving the best fit to the oxidation curves in the $\Delta-\psi$ plot, $\tilde{n}_{\mathrm{f}} \approx 2.50-0.25 i$ (cf. Fig. 1), closely resembles the values given in refs. ${ }^{26,27}$ for the oxides of iron at $\lambda=5461 \AA$.

\section{CONCLUSIONS}

Argon ion bombardment at relatively low energies $(<0.5 \mathrm{keV})$ can be used to remove the worked layer. High energy bombardment $(2 \mathrm{keV})$ simulates its presence, by causing an increase in oxidation rate and higher values of the real and imaginary part of the refractive index as compared with the undisturbed sample. The rate and extent of oxidation increases with increasing energy, dose and angle of incidence of the 
ion beam. The outermost part of the oxide is enriched in iron while the region near the substrate contains more nickel and chromium.

Ellipsometry proves to be a powerful tool in characterizing the damaged layer and monitoring the course of the oxidation. Its combination with ion bombardment and AES is useful to investigate the first stages of the oxidation process under well-defined conditions. Furthermore this combination is suitable for the determination of the depth profile and the sputtering yield of thin films.

Acknowledgements-The authors wish to thank N. C. Swart for carrying out part of the measurements in UHV system II, and J. J. Bloem, J. G. Broeze and M. A. de Jongh for technical assistance.

\section{REFERENCES}

1. G. C. Allen and R. K. WILD, J. Electron. Spectrosc. Relat. Phenom. 5, 409 (1974).

2. G. Betz, G. K. WeHNer, L. Toth and A. Joshi, J. appl. Phys. 45, 5312 (1974).

3. C. Jardin, Bui Minh Duc, J. P. Gauthier, G. Thollet and P. Michel, J. Electron Spectrosc. Relat. Phenom. 19, 213 (1980).

4. S. STORP and R. HoLM, Surf. Sci. 68, 10 (1977).

5. G. Blasek and M. Weihert, Surf. Sci. 82, 215 (1979).

6. D. Caplan and M. Cohen, Corros. Sci. 6, 321 (1966).

7. B. Kent and A. J. Davidson, Micro 74 supplement, Proc. RMS, 9, Pt. 4, 74 (1974).

8. M. K. Hossain, Corros. Sci. 19, 1031 (1979).

9. J. G. Post, G. F. Remmers, T. Fransen and P. J. Gellings (to be published).

10. R. M. AzzaM and N. M. BAsharA, Ellipsomerry and Polarized Light. North Holland, Amsterdam (1977).

11. W. E. J. Neal, Appl. Surf. Sci. 2, 445 (1979).

12. A. Joshi, L. E. Davis and P. W. PAlmberg, in Methods of Surface Analysis (ed. A. W. Czanderna). Elsevier, Amsterdam (1975).

13. T. A. Carlson, Photoelectron and Auger Spectroscopy. Plenum Press, New York (1978).

14. J. W. D. Martens, W. F. van Den Bogert and A. van Silfhout, Surf. Sci. 105, 275 (1981).

15. F. L. MCCRACKin, Fortram Program for Analysis of Ellipsometer Measurements, Natl. Bur. Std. (US), Techn. Note 497, Washington D.C. (1969).

16. G. A. Bootsma and F. MeYer, Surf. Sci. 14, 52 (1969).

17. F. H. P. M. Habraken, O. L. J. Guzeman and G. A. Bootsma, Surr. Sci. 96,482 (1980).

18. P. W. PAlmberg, G. E. Riach, R. E. Weber and N. C. McDonald, Handbook of Auger Electron Spectroscopy, Phys. El. Ind. Inc., Minnesota (1972).

19. G. K. WeHner, in Methods of Surface Analysis (ed. A. W. Czanderna). Elsevier, Amsterdam (1975).

20. V. T. Cherepin, A. A. Kosyachkov and M. A. Vasilyev, Surf. Sci. 58, 609 (1976).

21. T. M. Buck, in The Surface Chemistry of Metals and Semiconductors (ed. H. C. Gatos). Wiley, New York (1960).

22. R. M. HiLl and C. WeAver, Trans. Faraday Soc. 54, 1140 (1958).

23. D. E. AsPNes, E. KINSBRon and D. D. BACON, Phys. Rev. B21, 3290 (1980).

24. D. E. Aspnes and A. A. Studna, Surf. Sci. 96, 294 (1980).

25. Q. KIM and Y. S. PARK, Surf. Sci. 96, 307 (1980).

26. R. G. HART and G. W. Simmons, J. Vac. Sci. Technol. 15, 714 (1978).

27. G. Lewis and M. J. Chappell, Corros. Sci. 19, 73 (1979). 